\title{
A visão androcêntrica do mundo: elemento facilitador para o acesso dos homens às funções da gestão escolar
}

\author{
Andocentric referenced world: facilities to men get the \\ principal position in public schools
}

\section{Vanisse Simone Alves Corrêa ${ }^{1}$}

\section{Resumo:}

O artigo analisa a vantagem que os homens possuem quando competem com mulheres no acesso às funções da gestão escolar (direção e vice-direção) da Rede Municipal de Ensino de Curitiba. A visão androcêntrica do mundo leva os/as docentes a preferirem homens nas funções superiores da gestão escolar, mesmo quando estes são mais jovens, menos experientes e menos qualificados academicamente do que as mulheres. A disputa pelos cargos se dá em complexas relações de poder e gênero. A metodologia analisa dados empíricos advindos de informações sobre as eleições de 2008 para diretores/as e vice-diretores/ as, bem como dos microdados da Prova Brasil 2007 referentes aos/às diretores/as. Com suporte teórico em Bourdieu, Weber, Foucault e Scott o trabalho conclui que a visão masculina de mundo é elemento facilitador para a entrada de homens na gestão escolar, configurando uma situação de vantagem para os mesmos. Já para as mulheres, representa desvantagem profissional, mesmo na Educação, onde o número de mulheres é muito superior ao de homens.

Palavras-chave: Gestão escolar; Eleição para diretores/as; Visão androcêntrica de mundo; Relações de gênero e poder.

\begin{abstract}
:
The article analyzes the advantage that men have when competing with men in the access to the functions of school management in Municipal Schools of Curitiba. The andocentric view leads the teachers to prefer men in the higher functions of school management, even when they are younger, less experienced and less qualified academically than women. The competition for positions is given in complex power relations and gender. The methodology examines empirical data arising from information on the 2008 election for principals and microdata evidence regarding the 2007 Brazil National Evaluation. With theoretical support in Bourdieu, Weber, Foucault and Scott, this work concludes that the male vision of the world is a facilitator for the entry of men in school management, setting up a win situation for them. For women, this situation represents professional disadvantage, even in education, where the number of women is much higher than those of men.
\end{abstract}

Keywords: School Administration; Principal's election; Andocentric world; Gender and power relations. 
É sabido que a educação é uma profissão feminizada. Isso se dá, em parte, porque na tarefa de educar, sempre esteve, no imaginário popular, também a tarefa de cuidar. Nesse sentido, quem melhor que a mulher, dotada de características maternais, para ser a professora que educa e ensina, mas que também cuida e orienta?

(...) ser mulher é o requisito mais importante para ser uma competente cuidadora de crianças pequenas ou, ainda, o pressuposto de que ser portadora de um útero implica necessariamente a existência de um algo mais, chamado de instinto materno (MEYER, 2003, p. 19).

Ao longo de um conturbado processo histórico, as mulheres foram abrindo caminho na profissão docente e hoje, em nível nacional e municipal (especialmente no âmbito desta pesquisa), confirma-se a assertiva de que há muito mais mulheres do que homens no campo da Educação. Este entendimento, porém, para Muniz (2005) obscurece a imensa luta travada pelas mulheres para garantirem seu acesso aos bancos escolares, tanto no papel de alunas, como no de mestras, em intrincadas redes de relações de poder:

Afinal, trata-se de um processo de conformação de "corpos de mulheres" em "corpos de professoras" em que cada uma delas exercitou e sofreu efeitos das complexas redes de poder que atravessam o tecido social e que perpassam, principalmente, mas não exclusivamente, a instituição escolar, seus discursos, seus códigos, seus símbolos e suas práticas, imprimindo suas marcas (MUNIZ, 2005, p. 74).

O exercício do magistério pelas mulheres sempre foi balizado pelas regras que o Estado impunha. Um estado que era representado pelos homens e pela visão androcêntrica do mundo. Esses atributos definiam e modelavam o papel da mulher na função de professora, que nada mais era que uma extensão do trabalho doméstico e das funções de esposa e mãe, estereótipo eternizado pela imagem que a sociedade tinha da mulher.

Essa visão histórica é importante para o entendimento das desigualdades profissionais que até hoje são enfrentadas pelas mulheres. De fato, a História pode ajudar a compreender que mecanismos atuaram fortemente para perenizar a imagem da mulher professora, que se mantém até hoje praticamente intacta. Nesse processo, as mulheres tiveram um papel fundamental, apesar de sua "invisibilidade", da "autodestruição da memória feminina" e do "silêncio do relato", que sempre privilegiou a figura do homem (Perrot, 2008).

Assim, compreende-se que existe uma história das mulheres. Muitos fatores (científicos, sociológicos, políticos) contribuíram para colocar a mulher como objeto de estudo nas ciências humanas e na história. Isso aconteceu, em parte, porque a própria concepção de história mudou. Segundo Matos (2009), uma das maiores influências para essa abertura foi a descoberta do político no âmbito do cotidiano. A essa nova perspectiva, de politização do cotidiano, incorporou-se também um outro aspecto do relativismo pós-moderno, que ainda segundo a autora, "destrói a tradicional distinção entre o central e o periférico na história, contribuindo assim, para o desaparecimento progressivo do acontecimento histórico, do 'fato' como foco central de análise" (Matos, 2009, p. 279).

$\mathrm{Na}$ produção acadêmica atual, há uma tentativa de recuperar poderes e lutas femininas, de se repensar rótulos e estereótipos ${ }^{2}$, de se retomar a ação das mulheres na história, entendidas como sujeitos ativos (Matos, 2009, p. 282). Nesse movimento, as imagens de uma história linear, de dominação da mulher, vista como um ser pacífico, ocioso e confinado somente a um único papel social, vêm sendo questionadas. Para a autora, torna-se urgente e necessário ir além da dicotomia da história tradicional, que vê a mulher como vítima - a história linear - porém, sem esquecer-se da opressão histórica sobre as mulheres (Matos, 2009, p. 282).

Contemporaneamente, a participação da mulher na sociedade tem aumentado em todos os níveis sociais nos espaços antes considerados "masculinos". Apesar desse avanço, um grande contingente de mulheres ainda trabalha em setores de atividades muito bem delimitados histórica e socialmente, os quais agrupam as profissões ditas "femininas".

2Estereótipoéumconceito,umaimagempreconcebida e infundada sobre um determinado grupo social, que atribui a todos os seres desse grupo uma ou várias características, frequentemente depreciativas. Os estereótipos são usados principalmente para definir e limitar pessoas ou grupo de pessoas na sociedade. Sua aceitação é ampla e culturalmente difundida, o que o torna uma fonte geradora de preconceito e discriminação. Adaptado de http://pt.wikipedia.org/ wiki/Estere\%C3\%B3tipo (acessado em 15/01/2010). 
Segundo Abramo (2003, p.111), na América Latina, entre as décadas de 60 a 90, "o número de mulheres economicamente ativas mais que triplicou, aumentando de 18 para 57 milhões". Apesar disso, não se viu, na mesma proporção, uma diminuição das desigualdades profissionais entre homens e mulheres, inclusive no que diz respeito às questões salariais.

Opresente trabalho procura analisar um recorte dessa realidade, examinando um destes setores laborais considerado "feminino" - a Educação e procura responder à seguinte questão: Por que na educação, em particular na condução e liderança de processos políticos e de gestão, os homens ocupam/dominam com mais presença que as mulheres, considerando-se que se trata de um campo predominantemente de presença feminina? O que se observa, em muitas escolas, é que, embora apresentem um corpo docente predominantemente feminino, quem ascende às funções de direção e/ou vice-direção são os poucos homens que fazem parte do grupo.

A base teórica necessária envolve relações de poder e questões de gênero na gestão escolar e a base empírica desta pesquisa é a Rede Municipal de Ensino de Curitiba (RME), mais especificamente, os/ as profissionais da educação. Tal escolha se justifica pelo reduzido número de profissionais homens nessa rede de ensino (menos de $3 \%$ ), mas com uma presença proporcionalmente maior dos professores homens nas funções de direção escolar.

A pesquisa iniciou-se a partir da eleição para diretores/as da RME de Curitiba, ocorrida no dia 22/11/08, nas 171 escolas municipais de ensino fundamental. Os dados coletados apresentaram números surpreendentes. Há 10.109 profissionais da Educação na rede pública de ensino de Curitiba, sendo que destes, apenas 273 são homens (2,7\%). Mesmo com tão poucos homens, muitos conseguem se eleger diretores.

Importa saber como os homens, em número tão reduzido, conseguem chegar à função de direção e vice-direção nas escolas, as mais elevadas dentro da gestão escolar e saber quais motivos movem as pessoas a optarem por homens e não mulheres para essas funções. E mais ainda, considerando que a maioria dos/as profissionais são mulheres, o que as levou a escolherem homens? Quais mecanismos movimentam as estruturas de acesso à gestão escolar, compreendidas aí as questões de gênero e as relações de poder?

A dominação masculina em todas as áreas e a visão andocêntrica do mundo e de tudo o que consitui as relações sociais e por conseguinte, as relações de poder, leva a uma submissão a essa verdade naturalizada que os homens são os mais aptos a assumirem as funções de comando. As próprias mulheres não se dão conta de que agem no sentido de perpetuar esta visão de mundo. Para Bourdieu (2008):

(...) sempre vi na dominação masculina, e no modo como é imposta e vivenciada, o exemplo por excelência desta submissão paradoxal, resultante daquilo que eu chamo de violência simbólica, violência suave, insensível, invisível a suas próprias vítimas, que se exerce essencialmente pelas vias puramente simbólicas da comunicação e do conhecimento, ou mais precisamente, do desconhecimento, do reconhecimento ou, em última instância, do sentimento (Bourdieu, 2007, p. 7-8).

As mulheres e homens que preferem votar nos homens para as funções da gestão escolar o fazem de maneira instintiva, natural, quase automatizada. Não se reflete o porquê dessa preferência, simplesmente sente-se, intui-se que é melhor votar nos homens do que nas mulheres.

Neste trabalho a gestão é compreendida como uma rede de relações de poder, que se movimenta continuamente, alimentada pelas ações políticas das pessoas envolvidas.

A partir dos dados disponíveis na PROVA BRASIL 2007, este trabalho faz um perfil comparativo nacional entre diretores e diretoras. A seguir são analisadas as temáticas de poder e gênero na Rede Municipal de Ensino de Curitiba.

\section{Os dados da Prova Brasil 2007: 0 perfil nacional comparativo dos/as diretores/as}

Esta pesquisa trabalhou com questionários respondidos pelos/as diretores/as participantes da Prova Brasil 2007. As questões utilizadas referemse a sexo, idade, nível de escolaridade, salário, experiência na educação, e forma de provimento na função de diretor, com vistas a identificar e conhecer possíveis elementos que denunciassem a discriminação de gênero na gestão escolar. 


\section{- Sexo e Idade}

O número total de diretores/as respondentes da Prova Brasil foi de 47.350. Desses, 17,53\% são do sexo masculino. Há predominância das diretoras nas escolas públicas tanto de $4 .^{a}$ quanto de $8 .^{2}$ séries, onde o percentual é superior a $80 \%$.

No quesito idade, nas duas faixas que indicam os diretores mais jovens, faixa etária até $\mathbf{2 4}$ anos, há $0,7 \%$ de diretores contra $0,5 \%$ de diretoras. Já na faixa De $\mathbf{2 5}$ a 29 anos, 5,9\% são diretores e 3,5\% são diretoras. Nesses dados nacionais, fica evidente que os homens chegam com menos idade à direção e que o número de diretores é proporcionalmente maior do que o número de diretoras.

O maior número de diretores e diretoras encontrase na faixa etária dos 40 anos e acima $(62 \%$ de homens e $69 \%$ de mulheres). Com isso, é possível concluir que a carreira de diretor/a exige alguma experiência profissional, especialmente na condição de professor/a. Isso se configura quase como um pressuposto para se tornar diretor/a. Talvez porque com a experiência adquirida como professor/a, os/ as profissionais se sintam mais aptos/as a assumirem funções de comando e de maior responsabilidade.

\section{- Tempo de Trabalho/Experiência na Educação}

Conforme se observa na tabela 1, os homens levam mais vantagem dos que as mulheres porque conseguem chegar à direção com menos tempo de trabalho. Em quase todas as faixas da tabela o percentual masculino é maior. Entretanto, na faixa de maior experiência (mais de 15 anos), há uma evidente superioridade das mulheres. Isso deveria ser um fator de estímulo para que os salários femininos fossem maiores, o que não acontece como veremos adiante. A marca do preconceito contra a mulher, perpetuada pela visão androcêntrica de mundo, fica demonstrado por questões como essa. O gênero feminino aqui se configura como um elemento de desvantagem no mercado de trabalho.

\section{Tabela 1: Anos de trabalho na educação}

\begin{tabular}{|c|c|c|c|c|}
\hline & \multicolumn{4}{|c|}{ Sexo } \\
\cline { 2 - 5 } & Masculino & $\%$ & Feminino & $\%$ \\
\hline Há menos de 2 anos & 47 & 0,6 & 154 & 0,4 \\
\hline De 2 a 4 anos & 179 & 2,2 & 439 & 1,1 \\
\hline De 5 a 10 anos & 1462 & 17,7 & 3936 & 10,1 \\
\hline De 11 a 15 anos & 1665 & 20,2 & 5882 & 15,2 \\
\hline Mais de 15 anos & 4903 & 59,4 & 28376 & 73,2 \\
\hline Total & 8256 & 100 & 38787 & 100 \\
\hline
\end{tabular}

Fonte: MEC-INEP - Microdados Prova Brasil 2007.

\section{- Salário}

Aqui se percebe a gravidade da questão salarial. Os quatro salários mais altos da tabela 2 (de 5 a 6 SM até Mais de 8,2 SM) estão mais acessíveis aos homens do que às mulheres. $O$ mais alto salário da tabela 2 pertence a 11,5\% dos homens e somente a $8,4 \%$ das mulheres.

Isto mostra que em uma profissão na qual as mulheres são maioria absoluta, e apesar desse fato, elas ganham menos do que os homens para realizar a mesma atividade. Em tese, as redes públicas de ensino deveriam ter planos de carreira que tratassem o trabalhador de maneira igualitária, onde as oportunidades deveriam ser iguais para ambos os sexos, o que não parece acontecer.

Isso talvez ocorra porque, muito embora a entrada no cargo docente se faça por concurso público, as promoções são obtidas mediante indicação ou avaliações de desempenho. Essas, por serem feitas pelas chefias imediatas, têm algo de subjetivo, o juízo de valor, arraigado no inconsciente das pessoas, o que faz com que as mulheres fiquem em desvantagemnessahora. Seháhomens competindo, então, a probabilidade de uma mulher ser escolhida para o cargo diminui sobremaneira. Isto é motivado em parte, pela visão masculina de mundo, pela idéia de que tudo que é masculino é melhor, mais forte, mais competente e superior ao feminino.

A tabela 3 mostra o panorama dos salários dos/ as diretores/as, cruzando-se os dados atrelados à dependência municipal e estadual.

Conforme se percebe, as mulheres, tanto em nível municipal como no estadual, são as que recebem menos, pois superam os homens na faixa salarial mais baixa (1 SM). Há uma diferença marcante entre os gêneros nas duas dependências administrativas que apresenta pequenas nuances entre as redes, mas se configuram como tendência em ambas. Quanto à desigualdade nos rendimentos de homens e mulheres, Carreira (2007) esclarece:

As diferenças de rendimentos continuam sendo uma das faces mais perversas das desigualdades entre homens e mulheres no mercado de trabalho. Entre os países do Mercosul, o Brasil apresenta a maior brecha de rendimentos entre mulheres e homens. No setor informal, essa diferença ainda é maior. Em média, as mulheres brasileiras recebem $65 \%$ do que recebem os homens (Carreira, 2007, p. 18). 
Como uma ponta visível da discriminação contra as mulheres, a questão salarial é a mais grave e a mais cruel, na medida em que muitas mulheres atualmente mantêm sozinhas seus lares e seus salários são, muitas vezes, a única renda familiar. (Abramo, 2008) Além disso, continua a autora, quando não são o principal salário, as "mulheres contribuem significativamente para a renda familiar" (p. 39). Por esses motivos, o trabalho da mulher precisa ser valorizado e pago de maneira justa, além de ser equiparado ao salário dos homens.

Tabela 2: Salário dos diretores - Brasil

\begin{tabular}{|c|c|c|c|c|}
\hline \multirow{2}{*}{} & \multicolumn{4}{|c|}{ Sexo } \\
\cline { 2 - 5 } & Masculino & $\%$ & Feminino & $\%$ \\
\hline Até 1 SM & 46 & 0,6 & 283 & 0,7 \\
\hline De 1 a 1,3 SM & 113 & 1,4 & 677 & 1,7 \\
\hline De 1,3 a 1,8 SM & 296 & 3,6 & 1836 & 4,7 \\
\hline De 1,8 a 2,4 SM & 500 & 6,1 & 2668 & 6,9 \\
\hline De 2,4 a 2,9 SM & 602 & 7,3 & 3449 & 8,9 \\
\hline De 2,9 a 3,4 SM & 635 & 7,7 & 3436 & 8,9 \\
\hline De 3,4 a 3,9 SM & 590 & 7,2 & 2995 & 7,7 \\
\hline De 3,9 a 4,5 SM & 541 & 6,6 & 2860 & 7,4 \\
\hline De 4,5 a 5 SM & 670 & 8,1 & 3176 & 8,2 \\
\hline De 5 a 6 SM & 1401 & 17,0 & 6360 & 16,4 \\
\hline De 6 a 7,1 SM & 1039 & 12,6 & 4385 & 11,3 \\
\hline De 7,1 a 8,2 SM & 849 & 10,3 & 3312 & 8,6 \\
\hline Mais de 8,2 SM & 945 & 11,5 & 3251 & 8,4 \\
\hline Total & 8227 & 100 & 38688 & 100 \\
\hline
\end{tabular}

Fonte: MEC-INEP - Microdados Prova Brasil 2007.

\section{Tabela 3 - Salário de diretores/as nas redes estadual e municipal - Brasil}

\begin{tabular}{|c|c|c|c|c|}
\hline \multirow{2}{*}{} & \multicolumn{2}{|c|}{ Estadual } & \multicolumn{2}{c|}{ Municipal } \\
\cline { 2 - 5 } & Masculino & Feminino & Masculino & Feminino \\
\hline Até 1 SM & 0,5 & 0,6 & 0,7 & 0,8 \\
\hline De 1 a 1,3 SM & 0,7 & 0,7 & 2,3 & 2,5 \\
\hline De 1,3 a 1,8 SM & 1,0 & 1,4 & 7,0 & 7,1 \\
\hline De 1,8 a 2,4 SM & 1,8 & 2,8 & 11,8 & 9,7 \\
\hline De 2,4 a 2,9 SM & 3,9 & 5,0 & 11,9 & 11,6 \\
\hline De 2,9 a 3,4 SM & 5,7 & 6,4 & 10,5 & 10,5 \\
\hline De 3,4 a 3,9 SM & 5,7 & 6,4 & 10,5 & 10,5 \\
\hline De 3,9 a 4,5 SM & 7,2 & 7,6 & 5,8 & 7,1 \\
\hline De 4,5 a 5 SM & 9,6 & 9,7 & 6,2 & 7,0 \\
\hline De 5 a 6 SM & 21,7 & 22,5 & 10,5 & 11,7 \\
\hline De 6 a 7,1 SM & 16,3 & 16,4 & 7,6 & 7,4 \\
\hline De 7,1 a 8,2 SM & 13,1 & 11,5 & 6,5 & 6,3 \\
\hline Mais de 8,2 SM & 12,9 & 9,0 & 8,9 & 7,8 \\
\hline Total & 100 & 100 & 100 & 100 \\
\hline
\end{tabular}

Fonte: MEC-INEP - Microdados PROVA BRASIL 2007.

Obs.: Valores em percentuais

\section{- Escolaridade: Formação em pós-graduação}

Quanto à formação em pós-graduação, a tabela 4 demonstra que há muita equivalência neste quesito entre homens e mulheres, ainda que existam mais especialistas mulheres do que homens e mais mestres e doutores homens que mulheres. Os números comprobatórios desse equilíbrio são os $33,6 \%$ de homens e de mulheres que não fizeram ou não completaram nenhum curso de pós-graduação.

Tabela 4: Formação em pós-graduação - Brasil

\begin{tabular}{|c|c|c|c|c|}
\hline & \multicolumn{4}{|c|}{ Sexo } \\
\cline { 2 - 5 } & Masculino & $\%$ & Feminino & $\%$ \\
\hline Atualização & 486 & 6,0 & 1816 & 4,8 \\
\hline Especialização & 4668 & 57,2 & 22716 & 59,9 \\
\hline Mestrado & 219 & 2,7 & 556 & 1,5 \\
\hline Doutorado & 44 & 0,5 & 107 & 0,3 \\
\hline Não fiz ou não completei PG & 2747 & 33,6 & 12754 & 33,6 \\
\hline Total & 8164 & 100 & 37949 & 100 \\
\hline
\end{tabular}

Fonte: MEC-INEP - Microdados Prova Brasil 2007.

A tabela 5 demonstra algumas possibilidades de acesso à função de diretor. O que mais se destaca é a eleição. Os homens se elegem mais do que as mulheres no geral (tabela 5) e também proporcionalmente em nível estadual. Em nível municipal, há quase um empate, com uma ligeira vantagem das mulheres.

A indicação de políticos aparece em segundo lugar e ali o número de mulheres é maior do que o dos homens.

Já a tabela 6 mostra que mais mulheres ingressam na função pela seleção nas redes estaduais, porque nas municipais isso se inverte em favor dos homens.

Quanto às indicações para a função de direção, a tabela 6 demonstra que, na esfera municipal, há menos eleição e mais indicação de políticos, pois nesse reduto a política local age mais fortemente. Aqui há vantagem dos homens, pois eles são mais indicados para a função do que as mulheres.

Tabela 5: Provimento na função - Brasil

\begin{tabular}{|c|c|c|c|c|}
\hline & \multicolumn{4}{|c|}{ Sexo } \\
\cline { 2 - 5 } & Masculino & $\%$ & Feminino & $\%$ \\
\hline Seleção & 978 & 11,9 & 4252 & 11,0 \\
\hline Eleição apenas & 2109 & 25,7 & 8764 & 22,7 \\
\hline Seleção + Eleição & 1263 & 15,4 & 5323 & 13,8 \\
\hline Indicação de técnicos & 822 & 10,0 & 4067 & 10,5 \\
\hline Indicação de políticos & 1652 & 20,1 & 8699 & 22,6 \\
\hline Outras indicações & 764 & 9,3 & 4314 & 11,2 \\
\hline Outras formas & 625 & 7,6 & 3149 & 8,2 \\
\hline Total & 8213 & 100 & 38568 & 100 \\
\hline
\end{tabular}

Fonte: MEC-INEP - Microdados PROVA BRASIL 2007. 
Tabela 6: Provimento na função $x$ dependência administrativa - Brasil

\begin{tabular}{|c|c|c|c|c|}
\hline & \multicolumn{2}{|c|}{ Estadual } & \multicolumn{2}{|c|}{ Municipal } \\
\hline & Masculino & Feminino & Masculino & Feminino \\
\hline Seleção & 13,4 & 15,0 & 9,7 & 8,1 \\
\hline Eleição apenas & 31,8 & 26,8 & 17,1 & 19,7 \\
\hline Seleção + Eleição & 21,2 & 21,2 & 7,5 & 8,3 \\
\hline Indicação de técnicos & 6,0 & 5,7 & 15,6 & 14,2 \\
\hline Indicação de políticos & 11,1 & 11,1 & 32,5 & 31,1 \\
\hline Outras indicações & 7,3 & 8,8 & 12,2 & 13,0 \\
\hline Outras formas & 9,2 & 11,5 & 5,4 & 5,7 \\
\hline Total & 100 & 100 & 100 & 100 \\
\hline
\end{tabular}

Fonte: MEC-INEP - Microdados PROVA BRASIL 2007

Obs.: Valores em percentuais

Ao se observarem os dados em conjunto, percebe-se a discriminação de gênero na esfera da gestão escolar. Nas intrincadas relações sociais que acontecem dentro do espaço escolar, há uma tensão constante. Tais relações são, inegavelmente, relações de poder.

Os/as profissionais, ao se relacionarem entre si, expressam sua visão de mundo, seus discursos e atos são sempre políticos, mediados por suas crenças e experiências. Na educação, em que é grande a presença das mulheres, os homens conseguem chegar com mais facilidade aos maiores cargos da gestão escolar. Isso talvez decorra da visão masculina de mundo, na qual se acredita que os homens são mais competentes, mais capacitados a exercer o poder e, por conseguinte, mais aptos a comandar.

Perrot (1988), ao falar sobre a divisão dos poderes entre homens e mulheres, esclarece que os homens teriam o poder do Estado, o poder político, o poder de decidir, enfim. Quanto às mulheres, elas teriam os poderes informais (domésticos, de bastidores, etc). Essas crenças, baseadas em conceitos há muito perpetuados, ainda hoje fazem eco na gestão escolar. Os dados aqui apresentados não deixam dúvidas.

A busca de melhores condições de trabalho e de boas oportunidades profissionais para as mulheres é uma necessidade social. Atualmente grande parte das famílias é chefiada e sustentada por mulheres (Bruschini \& Lombardi, 2007).

A manutenção e a reprodução dos preconceitos e estereótipos relativos à mulher e seu papel no mercado de trabalho precisa ser superada. Entender e aceitar que a competência profissional não está ligada ao sexo é um avanço desejável para reduzir a discriminação contra a mulher e eliminar o preconceito de todas as organizações, inclusive das escolas.

\section{Gênero e Poder na Rede Municipal de Ensino (RME) de Curitiba: a influência do gênero na escolha dos/as dirigentes das escolas municipais}

O universo de professores na RME de Curitiba é um espaço rico de experiências femininas (97\% são mulheres). Em tese, o poder é ou deveria ser exercido por elas, que estão em maioria. Em contrapartida, os homens deveriam estar em desvantagem no que se refere à disputa por funções de mando. Para analisar esta questão, são apresentados e discutidos os dados referentes às eleições diretas para diretores/ as das escolas municipais (2008);

Em 22/11/08, 171 escolas municipais de Curitiba realizaram eleições para diretores/as e vices. Concorreram 269 chapas, totalizando $535^{3}$ candidatos/as. Desses/as candidatos/as, 10 eram do sexo masculino para o cargo de direção e 7 para o cargo de vice-direção. O Núcleo Regional da Educação $(\mathrm{NRE})^{4}$ que mais apresentou candidatos homens foi o do Bairro Novo, com 5 candidatos a diretor e 2 a vice-diretor, seguidos pelo NRE do Boa Vista, que apresentou 2 chapas com homens concorrendo à vice-direção. Os NREs do Boqueirão e do Portão apresentaram, cada um, uma única chapa com homens candidatos a diretores. Ambos conseguiram se eleger. O NRE Cajurú apresentou uma única chapa com homem concorrendo ao cargo de vice-direção. Esta chapa também conseguiu se eleger. A exceção é o NRE Pinheirinho, que apresentou duas chapas com homens candidatos, em uma concorrendo ao cargo de diretor e a na outra concorrendo ao cargo de vice-diretor e não elegeu nenhuma delas. Os NREs da Matriz e Santa Felicidade não tiveram candidatos do sexo masculino.

O número total de concorrentes aos cargos de diretores e vice-diretores foi de 535. Desses, somente 17 eram homens, ou seja, havia 518

3535 e não 538 porque 3 chapas apresentaram somente candidatos a diretor.

4 Em Curitiba, a Secretaria Municipal da Educação possui uma divisão administrativa, representada pelos Núcleos Regionais da Educação (NRE). No total há 9 núcleos que administram as escolas:. Bairro Novo, Portão, Boqueirão, CIC, Pinheirinho, Santa Felicidade, Boa Vista, Cajuru e Matriz. 
mulheres concorrendo, o que perfaz um percentual de $96,8 \%$ de mulheres e $3,2 \%$ de homens. O número de homens concorrentes, em termos percentuais, se aproxima bastante do número de homens professores na rede de ensino.

O resultado da eleição confirma a tese de que os homens conseguem chegar mais facilmente aos cargos superiores na gestão escolar. Dos 10 candidatos a diretor, 8 conseguiram vencer a disputa, o que dá um percentual de $80 \%$ de sucesso! Dos 7 candidatos a vice-diretor, 5 conseguiram se eleger, o que contabiliza $71,4 \%$ de êxito. Aqui é interessante notar que, quando disputaram a função mais alta (diretor), os homens tiveram mais resultado do que quando disputaram a função auxiliar (vice-diretor).

Se levarmos em conta o número de candidatos, independente do cargo ao qual concorriam, considerando que de 17, 14 foram eleitos, o percentual de aprovação masculina sobe para $82,35 \%$.

Nos NRE do Boqueirão, do Portão e do Cajurú, onde apenas uma única chapa com candidatos homens surgiu, uma em cada núcleo, todas elas conseguiram seeleger. Ostrês NREs contabilizaram 103 chapas. Ao fim da eleição, esses três núcleos elegeram 62 chapas. Entre estas, as três com candidatos homens se elegeram. É possível pensar que essas três chapas conseguiram se eleger porque, ao agregar homens como candidatos, agregaram também toda a imagem positiva que o masculino carrega.

Não é mera coincidência que as três, as únicas compostas com homens, elegeramse. O movimento que levou esses homens ao poder, como se fosse seu lugar natural, desde sempre, são as profundas estruturas simbólicas que permeiam as relações sociais. Dentre essas estruturas, a visão androcêntrica do mundo permanece como uma força subjetiva que leva as pessoas, homens ou mulheres, a eternizar a força do masculino. A vantagem que os homens levam em relação às mulheres se apresenta como uma coisa natural, motivada pelo fato de que são homens. Para Bourdieu (2007), a força da ordem masculina se impõe naturalmente, sem necessidade de justificação.

O gênero é a maneira inicial de dar significado às relações de poder (Scott, 1990, p. 14). É sabido que as relações de gênero demarcam as relações entre homens e mulheres, em todas as áreas. Na RME de Curitiba, no processo de escolha de homens e mulheres aos cargos de direção e vice-direção, fica evidente que o peso do gênero tem grande influência.

Como já foi dito, o número total de profissionais da educação da RME de Curitiba é de 10.109, sendo que destes, somente 273 são homens, aproximadamente $2,7 \%$. Com um percentual tão baixo em relação às mulheres, ainda assim, os homens conseguem galgar postos de direção e vice-direção nas escolas. Comandando 8 escolas de 171, eles têm o controle de aproximadamente $4,6 \%$ delas. Se contarmos os homens que estão na vice-direção (5), o número de escolas comandadas sobe para 13, então o percentual de controle vai para 7,6\%. É um número muito alto, comparado ao contingente masculino de profissionais (2,7\%), pois há aproximadamente e proporcionalmente $281 \%$ a mais homens diretores do que homens professores na RME de Curitiba.

\section{Considerações Finais}

Comesteestudo buscou-se identificar avantagem que os homens possuem quando competem com mulheres no acesso às funções da gestão escolar (direção e vice-direção) da Rede Municipal de Ensino de Curitiba. Para isso analisou-se, em um recorte específico, as eleições para diretores/as da RME de Curitiba e em que medida a visão androcêntrica de mundo leva os/as profissionais da educação preferirem homens nas funções superiores da gestão escolar. Foi evidenciado que os homens são favoritos para essas funções, ainda que sejam mais jovens, menos experientes e menos qualificados do que as mulheres, conforme os dados nacionais da Prova Brasil 2007.

De maneira geral, os dados demonstram a imensa vantagem que os homens têm para ascender às posições de comando na gestão escolar. Tal vantagem não é numérica, já que há mais mulheres diretoras do que homens diretores. É uma vantagem sutil, implícita, proporcional. Essa vantagem masculina, que se traduz em desvantagem para as mulheres, essa quase invisibilidade do fator vantajoso decorre de um entendimento de mundo que atribui ao masculino as funções de mando e poder.

Asuperioridade masculina acontece de maneira muito natural, quase sem ser questionada, quase imperceptível. Na esteira de Bourdieu (2007), a dominação masculina é exercida naturalmente, sem necessidade de justificação. Ou seja, os 
homens, cujo conceito no imaginário coletivo é sempre associado ao melhor, ao mais competente, ao mais correto, chegam muito mais facilmente ao poder ou funções de poder. E o grupo de homens e mulheres atua nesse sentido, fortalecendo essa crença, de maneira quase automática.

Os microdados da Prova Brasil 2007 trouxeram elementos importantes para se pensar a questão da gestão escolar associada ao perfil do/a dirigente de escola e confirmaram a existência do preconceito contra a mulher em termos nacionais.

A discussão passou pelo gênero e nessa perspectiva, demonstrou-se que as mulheres têm uma história e que ajudam a escrevê-la (Perrot, 2008), em meio a embates e relações de poder.

$\mathrm{Na}$ gestão escolar municipal de Curitiba, as mulheres e homens que lá se relacionam exercem o poder, uns sobre os outros, em um movimento contínuo (Foucault, 2004). Em termos numéricos, as mulheres são superiores aos homens. A mulher profissional da educação não é uma vítima dos homens, ela é atuante neste processo histórico e age politicamente. Porém, se há a manutenção da imagem da superioridade masculina e essa se reflete nas eleições, é porque as próprias mulheres ajudam a perenizar esses conceitos, auxiliando a criar e a manter para si mesmas, as barreiras quase invisíveis que as prejudicam na disputa de poder com os homens. A divisão sexual, fundamentada em uma visão androcêntrica de mundo (Bourdieu, 2007) leva à perpetuação da dominação masculina.

O fato de a educação ser uma profissão "feminizada" não impede os homens de assumirem os cargos hierarquicamente superiores na gestão escolar como se fosse o seu lugar natural.

Ao trazer esta discussão para o campo acadêmico, é possível promover uma reflexão sobre esta temática. Tal reflexão poderá possibilitar o diálogo entre homens e mulheres. Isso poderá levar os/as profissionais da educação a mudanças desejáveis de atitudes, na busca de uma sociedade mais justa e igualitária para todos.

\section{Referências Bibliográficas}

ABRAMO, L. A situação da mulher latino-americana - 0 mercado de trabalho no contexto da reestruturação. In: DELGADO, D. G.; CAPPELLIN, P.; SOARES, V. (org). Mulher e Trabalho - experiências de ação afirmativa. São Paulo: Boitempo Editorial, 2003.

. Inserção das mulheres no mercado de trabalho na América Latina: uma força de trabalho secundária? In: HIRATA, H.; SEGNINI, L. (org). Organização, trabalho e gênero. São Paulo: Editora Senac, 2007.

BOURDIEU, P. A dominação masculina. Rio de Janeiro: Bertrand Brasil, 2007.

BRUSCHINI, C.; LOMBARDI. M. R. Trabalho, educação e rendimentos das mulheres no Brasil em anos recentes. In: HIRATA, H.; SEGNINI, L. (org). Organização, trabalho e gênero. São Paulo: Editora Senac, 2007.

CARREIRA, D. Igualdade de gênero no mundo do trabalho: projetos brasileiros que fazem a diferença. São Paulo: Cortez; Brasília, DF: Fundo de Gênero Brasil - Canadá (FIG), 2004.

DURBIN, S. Women, power and the glass ceiling: current perspectives. [Disponível em http://jmi.sagepub.com (acessado em 10/01/09)

FOUCAULT, M. A vontade de saber. Rio de Janeiro:Ed. Graal, 1985.

. Vigiar e punir. Rio de Janeiro: Ed. Vozes, 2002.

Microfísica do poder. Rio de Janeiro: Ed. Graal, 2004.

INEP - Instituto Nacional de Estudos e Pesquisas Educacionais Anísio Teixeira. [Disponível em: http://umw.inep.gov.br.] (Acessado no período de 2008-2009].

MATOS, I. M. História das Mulheres e Gênero: usos e perspectivas. In: MELO, H. P. etal. (org). Olhares Feministas. Brasilia: Ministério da Educação: UNESCO, 2009. (Coleção Educação para todos; v. 10).

MEYER, D. E. Gênero e educação: teoria e política. In: LOURO, G.; NECKEL, J.F;;

GOELLNER, S. V. (org) Corpo, gênero e sexualidade - um debate contemporâneo na educação. Rio de Janeiro: Vozes, 2003.

PERROT, M. Os excluídos da história: operários, mulheres e prisoneiros. Rio de Janeiro, Paz e Terra, 1988.

Minha história das mulheres. São Paulo: Editora Contexto, 2008.

SCOT, J. Gênero, uma categoriaútil de análise histórica. Educação e realidade. V. 20, n. 2, Porto Alegre: Universidade Federal do Rio Grande do Sul, 1995. 